\title{
Plant parasitic nematode effectors target host defense and nuclear functions to establish feeding cells
}

\author{
Michaël Quentin*, Pierre Abad and Bruno Favery \\ Institut Sophia Agrobiotech, UMR INRA 1355 - Université Nice-Sophia Antipolis - CNRS 7254, Sophia Antipolis, France
}

\section{Edited by:}

Susana Rivas, Laboratoire des

Interactions Plantes-Microorganismes,

Centre National de la Recherche

Scientifique, France

\section{Reviewed by:}

Philippe Reymond, University of Lausanne, Switzerland

Mahmut Tör, University of Worcester, UK

\section{*Correspondence:}

Michaël Quentin, Institut Sophia Agrobiotech, UMR INRA 1355 Université Nice-Sophia Antipolis CNRS 7254, 400 routes des Chappes, F-06903 Sophia Antipolis, France.

e-mail: michael.quentin@sophia.inra.fr
Plant parasitic nematodes are microscopic worms, the most damaging species of which have adopted a sedentary lifestyle within their hosts. These obligate endoparasites have a biotrophic relationship with plants, in which they induce the differentiation of root cells into hypertrophied, multinucleate feeding cells (FCs). Effectors synthesized in the esophageal glands of the nematode are injected into the plant cells via the syringe-like stylet and play a key role in manipulating the host machinery. The establishment of specialized FCs requires these effectors to modulate many aspects of plant cell morphogenesis and physiology, including defense responses. This cell reprogramming requires changes to host nuclear processes. Some proteins encoded by parasitism genes target host nuclei. Several of these proteins were immunolocalized within FC nuclei or shown to interact with host nuclear proteins. Comparative genomics and functional analyses are gradually revealing the roles of nematode effectors. We describe here these effectors and their hypothesized roles in the unique feeding behavior of these pests.

\section{Keywords: root-knot nematodes, cyst nematodes, effectors, plant nuclei, feeding cells}

\section{INTRODUCTION}

Plant parasitic nematodes (PPNs) are small roundworms comprising about 4,000 species infesting roots of thousands of plant species and causing tremendous crop yield losses worldwide (Blok et al., 2008). The sedentary endoparasites, root-knot nematodes, (RKNs, Meloidogyne spp.) and cyst nematodes (CNs, Globodera spp. and Heterodera spp.), are among the most economically damaging PPNs. These parasites are obligate biotrophs that can feed only on the cytoplasm of living cells. Thus, both RKNs and CNs establish an intimate relationship with their host plants, inducing the redifferentiation of root cells into specialized multinucleate feeding cells (FCs). RKNs cause the formation and maintenance of five to seven giant cells, whereas CNs induce a syncytium (Figure 1). The first sign of giant cell induction by RKNs is the formation of one or several binucleate cells. These cells then go on to become multinucleate, through repeated nuclear divisions (karyokinesis) without cell division (Caillaud et al., 2008b). The hyperplasia and hypertrophy of the surrounding cells lead to the formation of the typical gall. In syncytia, the initial FC expands into the vascular tissue by the progressive and local dissolution of cell walls, resulting in the fusion of hundreds of neighboring root cells (Sobczak and Golinowski, 2011).

Fully differentiated FC is several hundred times the size of a normal root vascular cell. The cell walls thicken and ingrowths develop, facilitating solute exchange across the FC plasma membrane and sustaining nematode feeding until adult stages. Within the dense cytoplasm of the developing FC, subcellular organelles proliferate, their nuclei and nucleoli enlarge, and small secondary vacuoles are formed (Figure 1). FCs constitute the sole source of nutrients for the nematodes and are essential for their growth and reproduction. The complex changes in cellular morphology and physiology leading to FC establishment result from extensive changes to gene expression in the infected root cells. Patterns of host gene transcription have been compared by various techniques (Gheysen and Fenoll, 2002; Caillaud et al., 2008a), including, in particular, the recent genome-wide expression profiling of isolated giant cells or syncytia (Szakasits et al., 2009; Barcala et al., 2010; Damiani et al., 2012). These studies have led to the identification of many genes involved in diverse processes, such as cell cycle activation, cell wall modification, hormone and defense responses that are differentially expressed in FC formation. It remains unclear how this developmental switch allowing the nematodes to settle and resulting in changes to root cell morphology and the induction of FC occurs. However, it is now widely accepted that secreted nematode effectors play key roles in parasitism.

One of the characteristic features of PPNs is the presence of specialized esophageal gland cells allowing the production of proteins that are then secreted into the host through a hollow protrusible syringe-like stylet. The activity of these esophageal glands is developmentally regulated. Two subventral glands are particularly active during the preparasitic stages, secreting proteins involved in root invasion and larva migration, whereas a dorsal gland becomes hypertrophied and actively secretes effectors responsible for FC initiation and maintenance during the sedentary stages (Davis et al., 2008). In addition, proteins thought to be involved in parasitism are secreted into the apoplasm through the cuticle or via the chemosensory organs, the amphids. Various strategies have been used to identify nematode effectors. Proteomic approaches have been applied to purified $M$. incognita secretions (Bellafiore et al., 2008). Transcriptomic approaches, benefiting from recent advances in next-generation sequencing technologies, have made it possible to generate $\mathrm{CN}$ and RKN expressed sequence tags (ESTs) from various juvenile developmental stages 


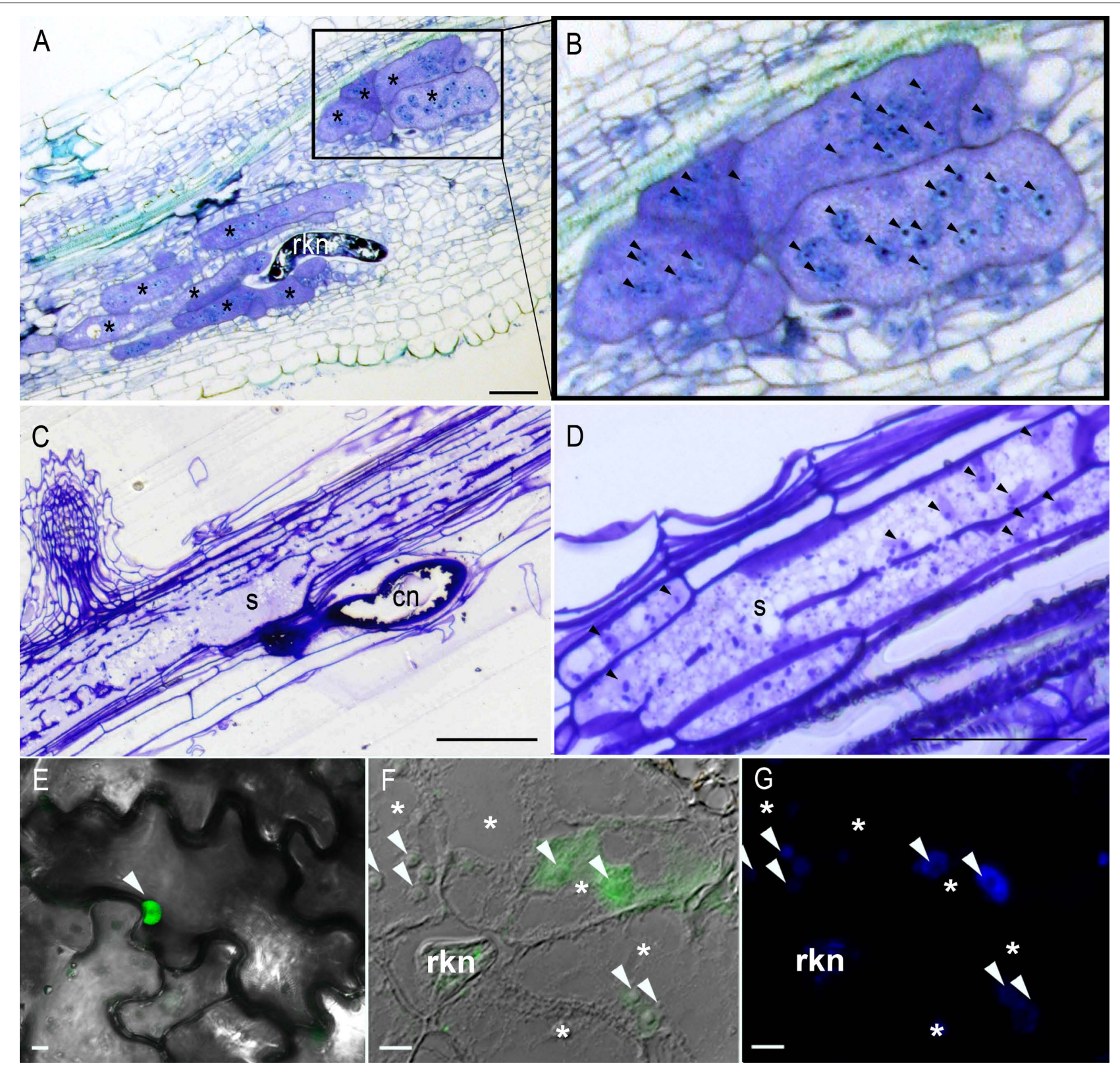

FIGURE 1 | Multinucleate and hypertrophied feeding cells induced by endoparasitic plant nematodes and nuclear localization of a RKN effector in planta. (A) Giant cells induced by the root-knot nematode Meloidogyne chitwoodi in pepper. (B) Multiple nuclei (arrowheads) are visible in the giant cells. (C,D) Syncytium induced by the cyst nematode H. schachtii in Arabidopsis. Cell wall dissolution results in a multinucleate cell. Toluidine blue-stained $(\mathbf{A}, \mathbf{B})$ or Crystal Violet-stained $(\mathbf{C}, \mathbf{D})$ longitudinal sections of infected roots $7(\mathbf{A}, \mathbf{B})$ or 10 (C,D) days after inoculation. (E) RKN effector MiEFF1::GFP accumulates in the nucleus (arrowhead) of tobacco epidermal leaf cells after agroinfiltration. (F) Immunolocalization of the secreted MiEFF1 in tomato galls 14 days after inoculation. FITC signal is observed at the tip of the stylet of a sedentary parasitic juvenile and in the nuclei (arrowheads) of giant cells. (G) DAPI-staining of nuclei of the section presented in (F). rkn, root-knot nematode; * giant cells; s, syncytium; cn, cyst nematode. Bars $=50 \mu \mathrm{m}$ (A-D) or $10 \mu \mathrm{m}$ (E-G).
(Roze et al., 2008; Jones et al., 2009; Jaouannet et al., 2012; Haegeman et al., 2013), infected plant tissues (Haegeman et al., 2013), or microaspiration of the cytoplasmic content of the esophageal glands (Wang et al., 2001; Gao et al., 2003; Huang et al., 2004) or isolated whole glands (Maier et al., 2013). Finally, comparative genomics approaches have facilitated a major breakthrough in effector identification. Two RKN genomes are now available, for M. incognita and M. hapla (Abad et al., 2008; Opperman et al., 2008) and increasing amounts of genomic information are being released for the soybean $\mathrm{CN} H$. glycines and the potato $\mathrm{CN} G$. pallida. The increasing availability of such data has led to the prediction of large effector repertoires. In situ hybridization studies have confirmed the specific expression of several of these putative effectors in the esophageal glands, suggesting their probable 
secretion into the host via the stylet and, thus, a role in infection. The identification of these effectors has made it possible to initiate functional analyses, which should make it possible to decipher the roles of these proteins in the targeting and manipulation of host functions (Haegeman et al., 2012; Hewezi and Baum, 2013). In this review, we describe nematode effectors that interact with host proteins or mimic host proteins, manipulating various aspects of plant physiology, including plant defense responses, and others that are targeted to the nucleus, where they may manipulate the nuclear machinery or bind to nucleotides (Table 1).

\section{NEMATODE EFFECTORS HIJACK KEY CELLULAR FUNCTIONS}

It remains unclear whether the nematode stylet perforates both the cell wall and the plasma membrane, to deliver effectors directly to the cytoplasm of the host cells. The apoplasm appears to be a major target of nematode effectors (Rosso et al., 2011; Vieira et al., 2011). However, nematode effectors may also be located within the host cells, where they may target different subcellular domains and assume highly diverse cellular functions (Haegeman et al., 2012; Hewezi and Baum, 2013). The first secreted proteins from PPNs to be characterized were cell wall-degrading and cell wall-modifying enzymes, such as $\beta$-1,4-endoglucanases, pectate lyases, polygalacturonases, and expansins, which are involved, in particular, in the invasion of root tissues by preparasitic juveniles and the migration of nematodes (Davis et al., 2011). These enzymes may also play an important role in FC formation, supporting the tremendous expansion of RKN-induced giant cells and facilitating syncytium formation. Effectors also target host enzymes to potentiate their function. Indeed, a $H$. schachtii (Hs) cellulose-binding protein, HsCBP, interacts with an Arabidopsis pectin methylesterase, potentially promoting the activity of this pectin-modifying enzyme or rendering cell wall polymers more accessible to other wall-degrading enzymes (Hewezi et al., 2008).

The de novo organogenesis underlying the construction of a nematode feeding site has a major impact on cell morphology and function as described above. Effectors mimicking plant compounds or binding to host proteins have been characterized. These molecules can affect plant signaling, hormone balance, and cell morphogenesis. The CNs secrete active CLAVATA3/ESR (CLE)like proteins (Wang et al., 2005, 2011). In plants, CLE-like peptides play an essential role in meristem differentiation. These effectors seem to be secreted into the cytoplasm of host cells, from which they are transported to the plant apoplasm, where they mimic plant CLE signaling peptides and interact at the plasma

Table 1 | Nematode effectors mentioned in this review, that target host functions to establish feeding cells.

\begin{tabular}{|c|c|c|c|c|}
\hline Effector & Predicted function & Host function & Identified plant target & Reference \\
\hline \multicolumn{5}{|l|}{ Globodera spp. } \\
\hline GpRBP-1 & SPRYSEC & Defense & NB-LRR-resistant protein potato GPA-2 & Sacco et al. (2009) \\
\hline GpCM & Chorismate mutase & Hormone and/or defense & - & Jones et al. (2003) \\
\hline GrVAP1 & Venom allergen protein & Defense & Papain-like cysteine protease Rcr3 & Lozano-Torres et al. (2012) \\
\hline GrSPRYSEC-19 & SPRYSEC & Defense & NB-LRR protein tomato SW5F & Rehman etal. (2009) \\
\hline GrCLE1 & CLE-like peptide & Hormone & Receptors AtCLV2 and AtBAM1 and 2 & Guo etal. (2011) \\
\hline \multicolumn{5}{|l|}{ Heterodera spp. } \\
\hline HgSYV46 & CLE-like peptide & Hormone & - & Wang etal. (2005) \\
\hline $\mathrm{Hg} 30 \mathrm{CO} 2$ & Unknown & Defense & $\beta$-1,3-endoglucanase & Hamamouch et al. (2012) \\
\hline $\mathrm{HgCM}$ & Chorismate mutase & Hormone and/or defense & - & Bekal etal. (2003) \\
\hline $\mathrm{HsCM}$ & Chorismate mutase & Hormone and/or defense & - & Vanholme etal. (2009) \\
\hline $\mathrm{HsCBP}$ & Cellulose-binding protein & Cell wall & Pectin methylesterase AtPME3 & Hewezi et al. (2008) \\
\hline HsCLE1 and 2 & CLE-like peptide & Hormone & - & Wang et al. (2011) \\
\hline Hs19C07 & Unknown & Hormone & Plasma membrane auxin influx transporter AtLAX3 & Lee et al. (2011) \\
\hline Hs10A06 & Unknown & Defense & Spermidine synthase AtSPDS2 & Hewezi et al. (2010) \\
\hline Hs4F01 & Annexin-like & Defense & Oxidoreductase of the 2OG-Fe(II) oxygenase family & Patel et al. (2010) \\
\hline HsUbil & Ubiquitin extension protein & Synthesis & - & Tytgat et al. (2004) \\
\hline \multicolumn{5}{|c|}{ Meloidogyne spp. } \\
\hline MiCM & Chorismate mutase & Hormone and/or defense & - & Huang etal. (2005) \\
\hline Mi8D05 & Unknown & Transport & Tonoplast intrinsic protein AtTIP2 & Xue etal. (2013) \\
\hline MiCRT & Calreticulin & Defense & - & Jaouannet et al. (2013) \\
\hline Mi16D10 & CLE-like peptide & Transcription & Scarecrow-like transcription factor AtSCL6 and 11 & Huang etal. (2006) \\
\hline MiEFF1 & Unknown & Unknown & - & Jaouannet et al. (2012) \\
\hline MjNULG1 & Unknown & Unknown & - & Lin etal. (2013) \\
\hline
\end{tabular}


membrane with leucine-rich repeat (LRR) receptor kinase family proteins, resulting in the formation and maintenance of syncytia (Guo etal., 2011). Another example of an effector having an impact on FC formation through the manipulation of host physiology is provided by Hs19C07, an effector that may modify hormone balance (Lee et al., 2011). Indeed, Hs19C07 interacts with the Arabidopsis plasma membrane auxin influx transporter LAX3, which modulates auxin influx in syncytia, thereby facilitating their development. Furthermore, both CNs and RKNs secrete proteins homologous to plant chorismate mutases (Bekal et al., 2003; Jones et al., 2003; Huang et al., 2005; Vanholme et al., 2009). The overexpression of nematode chorismate mutases in planta alters root growth (Doyle and Lambert, 2003), and it has been suggested that these effectors affect the auxin pool within the host cells. The recently characterized M. incognita effector Mi8D05 affects a different function of plant cells (Xue et al., 2013). Mi8D05 is essential for parasitism, as revealed by RNAi and overexpression approaches, and the overproduction of this effector strongly stimulates the growth of plant shoots. This effector has been shown to interact with a plant aquaporin tonoplast intrinsic protein (TIP2), suggesting a role in the regulation of solute and water transport within giant cells, promoting giant cell enlargement and nematode feeding.

Plants protect themselves against pathogen attacks through a combination of constitutive and induced strategies. The induction of plant defenses involves the recognition of compounds derived from the pathogen, called pathogen-associated molecular patterns (PAMPs). Pattern-triggered immunity (PTI) results from PAMP perception, leading to the activation of signaling pathways that restrict pathogen growth and promote host disease resistance (Jones and Dangl, 2006). No PAMPs have been described in nematodes, but secreted proteins and products of cell wall degradation may be recognized as such. Transcriptomic analysis has shown that a massive down-regulation of genes involved in plant defense is associated with the early stages of plant-nematode interaction (Jammes et al., 2005; Barcala et al., 2010; Damiani et al., 2012). This suggests that PPNs can suppress PTI. Various effectors that affect plant stress and defense responses have, indeed, been characterized (Smant and Jones, 2011). The nematode chorismate mutases mentioned above affect the plant shikimate pathway, thereby decreasing the synthesis of salicylic acid and phytoalexin through competition with chorismate, and preventing the triggering of host defense (Doyle and Lambert, 2003). Hs10A06 effector targets Arabidopsis spermidine synthase 2. Plants overproducing Hs10A06 are more susceptible to $\mathrm{CNs}$ and to bacterial and viral pathogens and produce smaller amounts of pathogenesisrelated (PR) proteins. Hs10A06 acts on salicylic acid signaling and the antioxidant machinery, thereby protecting nematodes against plant defense responses (Hewezi et al., 2010). Similarly, the Hs4F01 annexin-like effector is secreted into the cytosol (Patel et al., 2010), where it interacts with an oxidoreductase of the 2OG$\mathrm{Fe}(\mathrm{II})$ oxygenase family to prevent the triggering of host defense. Another CN effector, Hg30C02, interacts physically with a plant $\beta$-1,3-endoglucanase, a potential PR protein, and may thus be involved in defense suppression (Hamamouch et al., 2012). However, only M. incognita calreticulin (Mi-CRT), which suppresses defences induced by the PAMP elf18 when expressed in planta, has been shown to have a direct effect on PTI suppression (Jaouannet et al., 2013).

Plants have evolved resistance proteins that can recognize, either directly or indirectly, pathogen effectors, and induce effector-triggered immunity (ETI; Jones and Dangl, 2006). Several plant proteins conferring resistance to nematodes have been identified, mostly nucleotide-binding LRR (NB-LRR) proteins. However, very few nematode avirulence effectors have been identified (Smant and Jones, 2011). The CN effectors repertoire include a large family of secreted effectors containing a SPRY domain, named SPRYSECs (Jones et al., 2009; Rehman et al., 2009). One cytoplasmic G. pallida SPRYSEC (GpRBP-1) has been shown to be the avirulence target of the GPA-2 NB-LRR-resistant protein (Sacco et al., 2009). Remarkably, the GrSPRYSEC-19 protein has been shown to suppress the ETI mediated by several NB-LRR-resistant proteins, including GPA-2 (Postma et al., 2012). However, SPRYSEC-19 does not seem to mediate nematode resistance, despite interacting physically with SW5F, an SW5 NB-LRR-resistant protein from tomato (Rehman et al., 2009).

\section{NEMATODE EFFECTORS TARGET HOST CELL NUCLEI}

The manipulation of host cell processes, such as the cell cycle, gene expression, and immunity, almost certainly involves the targeting of the host nucleus by secreted effectors. Bioinformatic analyses of predicted effectors have revealed the presence of nuclear localisation signals (NLSs) in several secreted proteins from both CNs (Gao et al., 2003; Elling et al., 2007) and RKN (Huang et al., 2003; Roze et al., 2008), potentially allowing nuclear import. Proteomic studies have identified 486 proteins secreted by M. incognita, 66 of which were found to have a putative NLS, or DNA-binding or chromatin-binding domains (Bellafiore et al., 2008).

The use of green fluorescent protein (GFP)-fusions in transient expression assays has confirmed the nuclear localization of some of these effectors within plant cells (Elling et al., 2007; Jones et al., 2009). For instance, MiEFF1 is a small secreted protein of 122 amino acids (aa), with no predicted homologs in databases and no known functional domain. It has a NLS and localizes to the nucleus when transiently expressed in tobacco cells (Figure 1E; Jaouannet et al., 2012). Interestingly, some effectors are found in the cytoplasm when their full-length forms are produced in planta, but their truncated forms have a nuclear or nucleolar distribution, suggesting that they may be relocalized after modification of the protein within the host cell (Tytgat et al., 2004; Elling et al., 2007). In this way, the putative ubiquitin extension protein HsUbiI is delivered to the host cell cytoplasm, and the cleavable Cterminal domain of the protein is directed to the nucleolus, where it may be involved in ribosome synthesis and parasitism (Tytgat et al., 2004).

Recently, immunolocalization approaches have shown two RKN effectors to be effectively delivered to giant cell nuclei (Jaouannet et al., 2012; Lin et al., 2013). Immunostainings demonstrate MiEFF1 is produced in the dorsal esophageal gland of the nematode and is secreted through the stylet into the giant cells, in which it is transported into the nuclei (Figures 1F,G; Jaouannet et al., 2012). Similarly, M. javanica MjNULG1a is a 274 aa protein of unknown function with two predicted NLS localizing in FC nuclei. Transgenic plants overproducing MjNULG1a are more 
sensitive to RKN, and RNAi studies in planta have provided evidence of a role for this protein in nematode parasitism (Lin et al., 2013). Both MiEFF1 and MjNULG1a seem to be specific to early steps in parasitism, but it remains unclear whether these effectors are involved in giant cell formation. Identification of the host cell targets of these proteins is underway and should shed light on their functions.

Very few host targets of nematode effectors that could form part of the host nuclear machinery corrupted to promote parasitism have been identified to date with yeast two-hybrid approaches. The M. incognita effector Mi16D10, which encodes a novel 13-amino acid secretory peptide, appears to be important for nematode development, as shown by RNAi approaches, and it favors root growth when produced in planta. Two plant SCARECROW-like transcription factors that interact with the Mi16D10 protein have been identified (Huang et al., 2003, 2006). In plants, these transcription factors play a key role in regulating root meristem identity and root development, and Mi16D10 may thus function in the extensive transcriptional reprogramming responsible for FC ontogenesis. The CN effector Hs10A07 contains a NLS, but is generally located in the cytoplasm when produced in plant cells (Elling et al., 2007). However, Hs10A07 is translocated from the cytoplasm to the nucleus following its interaction with a specific Arabidopsis protein kinase. Once inside the nucleus, this Hs10A07 effector interacts with transcriptional regulators and plays a role in parasitism (Hewezi and Baum, 2013). The Hs32E03 effector is located in the nucleus following the transient expression of its gene in plant cells (Elling et al., 2007). During parasitism, this effector interacts with nuclear proteins, leading to its localization in nuclear bodies (Hewezi and Baum, 2013). However, it remains unclear how this particular pattern of nuclear localization promotes parasitism. Finally, some SPRYSEC proteins localize to the nucleus of plant cells when transiently produced in planta (Jones et al., 2009), and bimolecular fluorescence complementation assay have confirmed that SPRYSEC-19 interacts strongly with the tomato SW5F-resistant proteins in infiltrated tobacco cell nucleoli (Postma et al., 2012). The putative function of this interaction remains unknown, but it does not appear to be involved in the ETI suppression mediated by SPRYSEC-19.

\section{CONCLUSION AND PERSPECTIVES}

The identification of effectors is a major challenge in our understanding of the molecular aspects of plant-nematode interactions. Tremendous progress has been made toward the building of nematode effector repertoires since the completion of several genome sequencing. We still know little about the functions of these effectors and the host processes manipulated during the interaction to mediate the transformation of root cells into hypertrophied and multinucleate FCs. Functional characterization will be required

\section{REFERENCES}

Abad, P., Gouzy, J., Aury, J.-M., Castagnone-Sereno, P., Danchin, E. G. J., Deleury, E., et al. (2008). Genome sequence of the metazoan plant-parasitic nematode Meloidogyne incognita. Nat. Biotech. 26, 909-915.
Barcala, M., Garcia, A., Cabrera, J., Casson, S., Lindsey, K., Favery, B., et al. (2010). Early transcriptomic events in microdissected Arabidopsis nematode-induced giant cells. Plant J. 61, 698-712.

Bekal, S., Niblack, T. L., and Lambert, K. N. (2003). A chorismate mutase

to improve our understanding of the way in which these effectors promote host plant parasitism. Transformation procedures are currently lacking for PPNs, but such functional analysis should benefit from the recent development of RNAi approaches (Rosso et al., 2009), effector immunocytochemistry and the cellular imaging of feeding sites (Vieira et al., 2012a,b). A major breakthrough will result from identification of the plant targets of these effectors. Efforts to develop high-throughput approaches for such screening are already underway.

Host plant proteins targeted by effectors from many plant pathogenic microorganisms are being identified. It will be of particular interest to determine whether there are conserved parasitism strategies and whether nematodes and other plant pathogens target similar proteins. As obligate biotrophic parasites, nematodes must protect themselves against plant defenses and protect the host cells they need for feeding. PPNs may therefore target key components of the plant immune system corrupted during other plant-pathogen interactions. The GrVAP1 of CNs, Avr2 from the fungus Cladosporium fulvum and the EPIC1 and EPIC2B effectors from the oomycete Phytophthora infestans all target the same host papain-like cysteine protease, Rcr $3^{\mathrm{pim}}$ (Lozano-Torres et al., 2012), the tomato Cf- 2 protein mediating resistance to $G$. rostochiensis and C. fulvum in a Rcr $3^{\text {pim }}$-dependent manner.

Plant pathogens seem to target the plant nuclear machinery during infection (Bierne and Cossart, 2012; Caillaud et al., 2012; Deslandes and Rivas, 2012). Recent studies have shown that nematode effectors may indeed be localized to host nuclei or interact with host nuclear proteins. In addition, Hewezi and Baum (2013) have suggested that CN effectors recruit proteins involved in nucleocytoplasmic movement and nuclear dynamic during the parasitization of their hosts. These processes play an important role in several plant-pathogen interactions (Wiermer et al., 2007; Rivas, 2012). The identification of nematode effectors likely to bind DNA directly and affect host gene expression remains a major challenge. The molecular characterization of effectors and their plant targets is a key step toward understanding the factors determining nematode virulence, plant susceptibility or immunity and host range, and will open up new perspectives for controlling nematodes and other agronomically important pathogens.

\section{ACKNOWLEDGMENTS}

We wish to thank Miroslaw Sobczak (Warsaw University of Life Sciences) for the syncytium pictures, Caroline Djian-Caporalino for the giant cells images, and Maëlle Jaouannet and Marc Magliano for MiEFF1 immunolocalization pictures. Our work is funded by the French ANR-08-GENM-014 (SCRIPS) and ANR PCS-08-GENO-166 (NEMATARGET), and carried out in the SIGNALIFE Laboratoire d'Excellence (LabEx).

from the soybean cyst nematode Heterodera glycines shows polymorphisms that correlate with virulence. Mol. Plant Microbe Interact. 16 , 439-446.

Bellafiore, S., Shen, Z., Rosso, M.N., Abad, P., Shih, P., and Briggs, S. P. (2008). Direct Identification of the Meloidogyne incognita secretome reveals proteins with host cell reprogramming potential. PLoS Pathog. 4:e1000192. doi: 10.1371/journal. ppat.1000192

Bierne, H., and Cossart, P. (2012). When bacteria target the nucleus: the emerging family of 
nucleomodulins. Cell. Microbiol. 14, 622-633.

Blok, V. C., Jones, J. T., Phillips, M. S., and Trudgill, D. L. (2008). Parasitism genes and host range disparities in biotrophic nematodes: the conundrum of polyphagy versus specialisation. Bioessays 30, 249-259.

Caillaud, M.-C., Dubreuil, G., Quentin, M., Perfus-Barbeoch, L., Lecomte, P., de Almeida Engler, J., et al. (2008a). Root-knot nematodes manipulate plant cell functions during a compatible interaction. J. Plant Physiol. 165, 104-113.

Caillaud, M.-C., Lecomte, P., Jammes, F., Quentin, M., Pagnotta, S., Andrio, E., et al. (2008b). MAP653 microtubule-associated protein is essential for nematode-induced giant cell ontogenesis in Arabidopsis. Plant Cell 20, 423-437.

Caillaud, M.-C., Wirthmueller, L., Fabro, G., Piquerez, S. J. M., Asai, S., Ishaque, N., et al. (2012). Mechanisms of nuclear suppression of host immunity by effectors from the Arabidopsis downy mildew pathogen Hyaloperonospora arabidopsidis (Hpa). Cold Spring Harb. Symp. Quant. Biol. doi: 10.1101/sqb. 2012.1177.015115 [Epub ahead of print].

Damiani, I., Baldacci-Cresp, F., Hopkins, J., Andrio, E., Balzergue, S., Lecomte, P., et al. (2012). Plant genes involved in harbouring symbiotic rhizobia or pathogenic nematodes. New Phytol. 194, 511-522.

Davis, E., Haegeman, A., and Kikuchi, T. (2011). "Degradation of the plant cell wall by nematodes," in Genomics and Molecular Genetics of Plant-Nematode Interactions, eds J. Jones, G. Gheysen, and C. Fenoll (Berlin: Springer), 225-272.

Davis, E. L., Hussey, R. S., Mitchum, M. G., and Baum, T. J. (2008). Parasitism proteins in nematode-plant interactions. Curr. Opin. Plant Biol. 11, 360-366.

Deslandes, L., and Rivas, S. (2012). Catch me if you can: bacterial effectors and plant targets. Trends Plant Sci. 17, 644-655.

Doyle, E. A., and Lambert, K. N. (2003). Meloidogyne javanica chorismate mutase 1 alters plant cell development. Mol. Plant Microbe Interact. 16, 123-131.

Elling, A. A., Davis, E. L., Hussey, R. S., and Baum, T. J. (2007). Active uptake of cyst nematode parasitism proteins into the plant cell nucleus. Int. J. Parasitol. 37, 1269-1279.

Gao, B., Allen, R., Maier, T., Davis, E. L., Baum, T. J., and Hussey, R. S. (2003). The parasitome of the phytonematode Heterodera glycines. Mol. Plant Microbe Interact. 16, 720-726.

Gheysen, G., and Fenoll, C. (2002). Gene expression in nematode feeding sites. Annu. Rev. Phytopathol. 40, 191-219.

Guo, Y., Ni, J., Denver, R., Wang, X., and Clark, S. E. (2011). Mechanisms of molecular mimicry of plant CLE peptide ligands by the parasitic nematode Globodera rostochiensis. Plant Physiol. 157, 476-484.

Haegeman, A., Bauters, L., Kyndt, T., Rahman, M. M., and Gheysen, G. (2013). Identification of candidate effector genes in the transcriptome of the rice root knot nematode Meloidogyne graminicola. Mol. Plant Pathol. doi: 10.1111/mpp.12014 [Epub ahead of print].

Haegeman, A., Mantelin, S., Jones, J. T., and Gheysen, G. (2012). Functional roles of effectors of plant-parasitic nematodes. Gene 492, 19-31.

Hamamouch, N., Li, C., Hewezi, T., Baum, T. J., Mitchum, M. G., Hussey, R. S., et al. (2012). The interaction of the novel 30C02 cyst nematode effector protein with a plant Beta1,3-endoglucanase may suppress host defence to promote parasitism. J. Exp. Bot. 63, 3683-3695.

Hewezi, T., and Baum, T. J. (2013). Manipulation of plant cells by cyst and root-knot nematode effectors. Mol. Plant Microbe Interact. 26, 9-16. Hewezi, T., Howe, P., Maier, T. R., Hussey, R. S., Mitchum, M. G., Davis E. L., et al. (2008). Cellulose binding protein from the parasitic nematode Heterodera schachtii interacts with Arabidopsis pectin methylesterase: cooperative cell wall modification during parasitism. Plant Cell 20, 3080-3093.

Hewezi, T., Howe, P. J., Maier, T. R., Hussey, R. S., Mitchum, M. G., Davis, E. L., et al. (2010). Arabidopsis spermidine synthase is targeted by an effector protein of the cyst nematode Heterodera schachtii. Plant Physiol. 152, 968-984.

Huang, G., Dong, R., Allen, R., Davis, E. L., Baum, T. J., and Hussey, R. S. (2005). Two chorismate mutase genes from the root-knot nematode Meloidogyne incognita. Mol. Plant Pathol. 6, 23-30.

Huang, G., Dong, R., Allen, R., Davis, E. L., Baum, T. J., and Hussey, R. S. (2006). A root-knot nematode secretory peptide functions as a ligand for a plant transcription factor. $\mathrm{Mol}$. Plant Microbe Interact. 19, 463-470.

Huang, G., Dong, R., Maier, T., Allen, R., Davis, E. L., Baum, T. J., et al. (2004). Use of solid-phase subtractive hybridization for the identification of parasitism gene candidates from the root-knot nematode Meloidogyne incognita. Mol. Plant Pathol. 5, 217-222.

Huang, G., Gao, B., Maier, T., Allen, R., Davis, E. L., Baum, T. J., etal. (2003). A profile of putative parasitism genes expressed in the esophageal gland cells of the rootknot nematode Meloidogyne incognita. Mol. Plant Microbe Interact. 16, 376-381.

Jammes, F., Lecomte, P., de AlmeidaEngler, J., Bitton, F., MartinMagniette, M.-L., Renou, J. P., et al. (2005). Genome-wide expression profiling of the host response to root-knot nematode infection in Arabidopsis. Plant J. 44, 447-458.

Jaouannet, M., Magliano, M., Arguel, M. J., Gourgues, M., Evangelisti, E., Abad, P., et al. (2013). The root-knot nematode calreticulin Mi-CRT is a key effector in plant defense suppression. Mol. Plant Microbe Interact. 26, 97-105.

Jaouannet, M., Perfus-Barbeoch, L., Deleury, E., Magliano, M., Engler, G. Vieira, P., et al. (2012). A root-knot nematode-secreted protein is injected into giant cells and targeted to the nuclei. New Phytol. 194, 924-931.

Jones, J. D. G., and Dangl, J. L. (2006). The plant immune system. Nature 444, 323-329.

Jones, J. T., Furlanetto, C., Bakker, E., Banks, B., Blok, V., Chen, Q., et al. (2003). Characterization of a chorismate mutase from the potato cyst nematode Globodera pallida. Mol. Plant Pathol. 4, 43-50.

Jones, J. T., Kumar, A., Pylypenko, L. A., Thirugnanasambandam, A., Castelli, L., Chapman, S., etal. (2009). Identification and functional characterization of effectors in expressed sequence tags from various life cycle stages of the potato cyst nematode Globodera pallida. Mol. Plant Pathol. 10, 815-828.

Lee, C., Chronis, D., Kenning, C., Peret, B., Hewezi, T., Davis, E. L., et al. (2011). The novel cyst nematode effector protein 19C07 interacts with the Arabidopsis auxin influx transporter LAX3 to control feeding site development. Plant Physiol. 155, 866-880.

Lin, B., Zhuo, K., Wu, P., Cui, R., Zhang, L.-H., and Liao, J. (2013). A novel effector protein, MJ-NULGla, targeted to giant cell nuclei plays a role in Meloidogyne javanica parasitism. Mol. Plant Microbe Interact. 26, 55-66.

Lozano-Torres, J. L., Wilbers, R. H. P., Gawronski, P., Boshoven, J. C.,
Finkers-Tomczak, A., Cordewener, J. H. G., etal. (2012). Dual disease resistance mediated by the immune receptor $\mathrm{Cf}-2$ in tomato requires a common virulence target of a fungus and a nematode. Proc. Natl. Acad. Sci. U.S.A. 109, 10119-10124.

Maier, T. R., Hewezi, T., Peng, J., and Baum, T. J. (2013). Isolation of whole esophageal gland cells from plant-parasitic nematodes for transcriptome analyses and effector identification. Mol. Plant Microbe Interact. 26, 31-35.

Opperman, C. H., Bird, D. M., Williamson, V. M., Rokhsar, D. S., Burke, M., Cohn, J., et al. (2008). Sequence and genetic map of Meloidogyne hapla: a compact nematode genome for plant parasitism. Proc. Natl. Acad. Sci. U.S.A. 105, 14802-14807.

Patel, N., Hamamouch, N., Li, C., Hewezi, T., Hussey, R. S., Baum, T. J., et al. (2010). A nematode effector protein similar to annexins in host plants. J. Exp. Bot. 61, 235-248.

Postma, W. J., Slootweg, E. J., Rehman, S., Finkers-Tomczak, A., Tytgat, T. O. G., van Gelderen, K., et al. (2012). The effector SPRYSEC-19 of Globodera rostochiensis suppresses CC-NB-LRR-mediated disease resistance in plants. Plant Physiol. 160, 944-954.

Rehman, S., Postma, W., Tytgat, T., Prins, P., Qin, L., Overmars, H., et al. (2009). A secreted SPRY domaincontaining protein (SPRYSEC) from the plant-parasitic nematode Globodera rostochiensis interacts with a CC-NB-LRR protein from a susceptible tomato. Mol. Plant Microbe Interact. 22, 330-340.

Rivas, S. (2012). Nuclear dynamics during plant innate immunity. Plant Physiol. 158, 87-94.

Rosso, M. N., Jones, J. T., and Abad, P. (2009). RNAi and functional genomics in plant parasitic nematodes. Annu. Rev. Phytopathol. 47, 207-232.

Rosso, M. N., Vieira, P., de almeida Engler, J., and Castagnone-Sereno, P. (2011). Proteins secreted by rootknot nematodes accumulate in the extracellular compartment during root infection. Plant Signal. Behav. 6, 1232-1234.

Roze, E., Hanse, B., MIitreva, M., Van Holme, B., Bakker, J., and Smant, G. (2008). Mining the secretome of the root-knot nematode Meloidogyne chitwoodi for candidate parasitism genes. Mol. Plant Pathol. 9, 1-10.

Sacco, M. A., Koropacka, K., Grenier, E., Jaubert, M. J., Blanchard, A., Goverse, A., et al. (2009). The cyst nematode 
SPRYSEC protein RBP-1 elicits Gpa2and RanGAP2-dependent plant cell death. PLoS Pathog. 5:e1000564. doi: 10.1371/journal.ppat.1000564

Smant, G., and Jones, J. (2011). "Suppression of plant defences by nematodes," in Genomics and Molecular Genetics of Plant-Nematode Interactions, eds J. Jones, G. Gheysen, and C. Fenoll (Berlin: Springer), 273-286.

Sobczak, M., and Golinowski, W. (2011). "Cyst nematodes and syncytia," in Genomics and Molecular Genetics of Plant-Nematode Interactions, eds J. D. Jones, G. Gheysen, and C. Fenoll (Berlin: Springer), 61-82.

Szakasits, D., Heinen, P., Wieczorek, K., Hofmann, J., Wagner, F., Kreil, D. P., etal. (2009). The transcriptome of syncytia induced by the cyst nematode Heterodera schachtii in Arabidopsis roots. Plant J. 57, 771-784.

Tytgat, T., Vanholme, B., De Meutter, J., Claeys, M., Couvreur, M., Vanhoutte, I., et al. (2004). A new class of ubiquitin extension proteins secreted by the dorsal pharyngeal gland in plant parasitic cyst nematodes. Mol. Plant Microbe Interact. 17, 846-852.
Vanholme, B., Kast, P., Haegeman, A., Jacob, J., Grunewald, W., and Gheysen, G. (2009). Structural and functional investigation of a secreted chorismate mutase from the plant-parasitic nematode Heterodera schachtii in the context of related enzymes from diverse origins. $\mathrm{Mol}$. Plant Pathol. 10, 189-200.

Vieira, P., Danchin, E. G. J., Neveu, C., Crozat, C., Jaubert, S., Hussey, R. S. et al. (2011). The plant apoplasm is an important recipient compartment for nematode secreted proteins. J. Exp. Bot. 62, 1241-1253.

Vieira, P., Engler, G., and de Almeida Engler, J. (2012a). Whole-mount confocal imaging of nuclei in giant feeding cells induced by root-knot nematodes in Arabidopsis. New Phytol. 195, 488-496.

Vieira, P., Banora, M. Y., CastagnoneSereno, P., Rosso, M. -N., Engler, G. and de Almeida Engler, J. (2012b). An immunocytochemical procedure for protein localization in various nematode life stages combined with plant tissues using methylacrylateembedded specimens. Phytopathology 102, 990-996.

Wang, J., Reploge, A., Hussey, R., Baum, T., Wang, X., Davis, E. L., et al.
(2011). Identification of potential host plant mimics of CLAVATA3/ESR (CLE)-like peptides from the plantparasitic nematode Heterodera schachtii. Mol. Plant Pathol. 12, 177-186.

Wang, X., Allen, R., Ding, X., Goellner, M., Maier, T., de Boer, J. M. et al. (2001). Signal peptide-selection of cDNA cloned directly from the esophageal gland cells of the soybean cyst nematode Heterodera glycines. Mol. Plant Microbe Interact. 14, 536-544.

Wang, X., Mitchum, M. G., Gao, B., Li, C., Diab, H., Baum, T. J., et al. (2005). A parasitism gene from plant-parasitic nematode with function similar to CLAVATA3/ESR (CLE) of Arabidopsis thaliana. Mol. Plant Pathol. 6, 187-191.

Wiermer, M., Palma, K., Zhang, Y., and Li, X. (2007). Should I stay or should I go? Nucleocytoplasmic trafficking in plant innate immunity. Cell. Microbiol. 9, 1880 1890.

Xue, B., Hamamouch, N., Li, C. Huang, G., Hussey, R. S., Baum, T. J., et al. (2013). The 8D05 parasitism gene of Meloidogyne incognita is required for successful infection of host roots. Phytopathology 103, 175-181.

Conflict of Interest Statement: The authors declare that the research was conducted in the absence of any commercial or financial relationships that could be construed as a potential conflict of interest.

Received: 31 January 2013; paper pending published: 13 February 2013; accepted: 27 February 2013; published online: 13 March 2013

Citation: Quentin M, Abad P and Favery $B$ (2013) Plant parasitic nematode effectors target host defense and nuclear functions to establish feeding cells. Front. Plant Sci. 4:53. doi: 10.3389/fpls. 2013.00053

This article was submitted to Frontiers in Plant-Microbe Interaction, a specialty of Frontiers in Plant Science.

Copyright (c) 2013 Quentin, Abad and Favery. This is an open-access article distributed under the terms of the Creative Commons Attribution License, which permits use, distribution and reproduction in other forums, provided the original authors and source are credited and subject to any copyright notices concerning any third-party graphics etc. 